\title{
Seabed video and still images from the northern Weddell Sea and the western flanks of the Powell Basin
}

\author{
Autun Purser ${ }^{1}$, Simon Dreutter ${ }^{1}$, Huw Griffiths ${ }^{2}$, Laura Hehemann ${ }^{1}$, Kerstin Jerosch ${ }^{1}$, \\ Axel Nordhausen ${ }^{3}$, Dieter Piepenburg ${ }^{1,4}$, Claudio Richter ${ }^{1}$, Henning Schröder ${ }^{1}$, and Boris Dorschel ${ }^{1}$ \\ ${ }^{1}$ Alfred Wegener Institute, Helmholtz Centre for Polar and Marine Research, \\ Am Handelshafen 12, 26570 Bremerhaven, Germany \\ ${ }^{2}$ British Antarctic Survey, High Cross, Madingley Rd, Cambridge, CB3 OET, UK \\ ${ }^{3}$ Max Planck Institute for Marine Microbiology, Celsiusstrasse 1, 28359 Bremen, Germany \\ ${ }^{4}$ Helmholtz Institute for Functional Marine Biodiversity at the University of Oldenburg (HIFMB), \\ Carl-von-Ossietzky-Str. 9-11, 26129 Oldenburg, Germany
}

Correspondence: Autun Purser (autun.purser@awi.de)

\author{
Received: 11 August 2020 - Discussion started: 13 October 2020 \\ Revised: 4 January 2021 - Accepted: 10 January 2021 - Published: 23 February 2021
}

\begin{abstract}
Research vessels equipped with fibre optic and copper-cored coaxial cables support the live onboard inspection of high-bandwidth marine data in real time. This allows for towed still-image and video sleds to be equipped with latest-generation higher-resolution digital camera systems and additional sensors. During RV Polarstern expedition PS118 in February-April 2019, the recently developed Ocean Floor Observation and Bathymetry System (OFOBS) of the Alfred Wegener Institute was used to collect still-image and video data from the seafloor at a total of 11 predominantly ice-covered locations in the northern Weddell Sea and Powell Basin. Still images of 26-megapixel resolution and HD (high-definition) quality video data were recorded throughout each deployment. In addition to downward-facing video and still-image cameras, the OFOBS also mounted side-scanning and forward-facing acoustic systems, which facilitated safe deployment in areas of high topographic complexity, such as above the steep flanks of the Powell Basin and the rapidly shallowing, iceberg-scoured Nachtigaller Shoal. To localise collected data, the OFOBS system was equipped with a Posidonia transponder for ultra-short baseline triangulation of OFOBS positions. All images are available from: https://doi.org/10.1594/PANGAEA.911904 (Purser et al., 2020).
\end{abstract}

\section{Introduction}

Recent studies indicate that climate change processes in the maritime Antarctic are accelerating, leading to the increasing retreat of the ice sheets of the eastern coast of the Antarctic Peninsula and the near disintegration of the ice shelves Larsen A in 1995 and Larsen B in 2002 (Rott et al., 1996; Scambos et al., 2013; Shepherd et al., 2003), as well as the break-off of giant icebergs from Larsen C (Han et al., 2019; Shepherd et al., 2003; Skvarca, 1993). This change in ice coverage has resulted in spatially extensive habitat change both above and below water, with many processes from light penetration, ocean stratification, surface productivity and food transportation pathways being affected (Barnes and
Tarling, 2017; Chaabani et al., 2019; Fillinger et al., 2013; Griffiths et al., 2017; Gutt et al., 2019). By assessing the seafloor habitats and associated benthic fauna communities in these areas recently free of permanent ice cover with the Ocean Floor Observation and Bathymetry System (OFOBS) of the Alfred Wegener Institute (AWI), Helmholtz Centre for Polar and Marine Research (Germany) (Fig. 1), the ecological effects of climate-driven ice shelf loss can be studied. The OFOBS is a towed platform capable of deployment in moderately ice-covered conditions and capable of concurrently collecting acoustic, video and still-image data from the seafloor (Purser et al., 2018). 


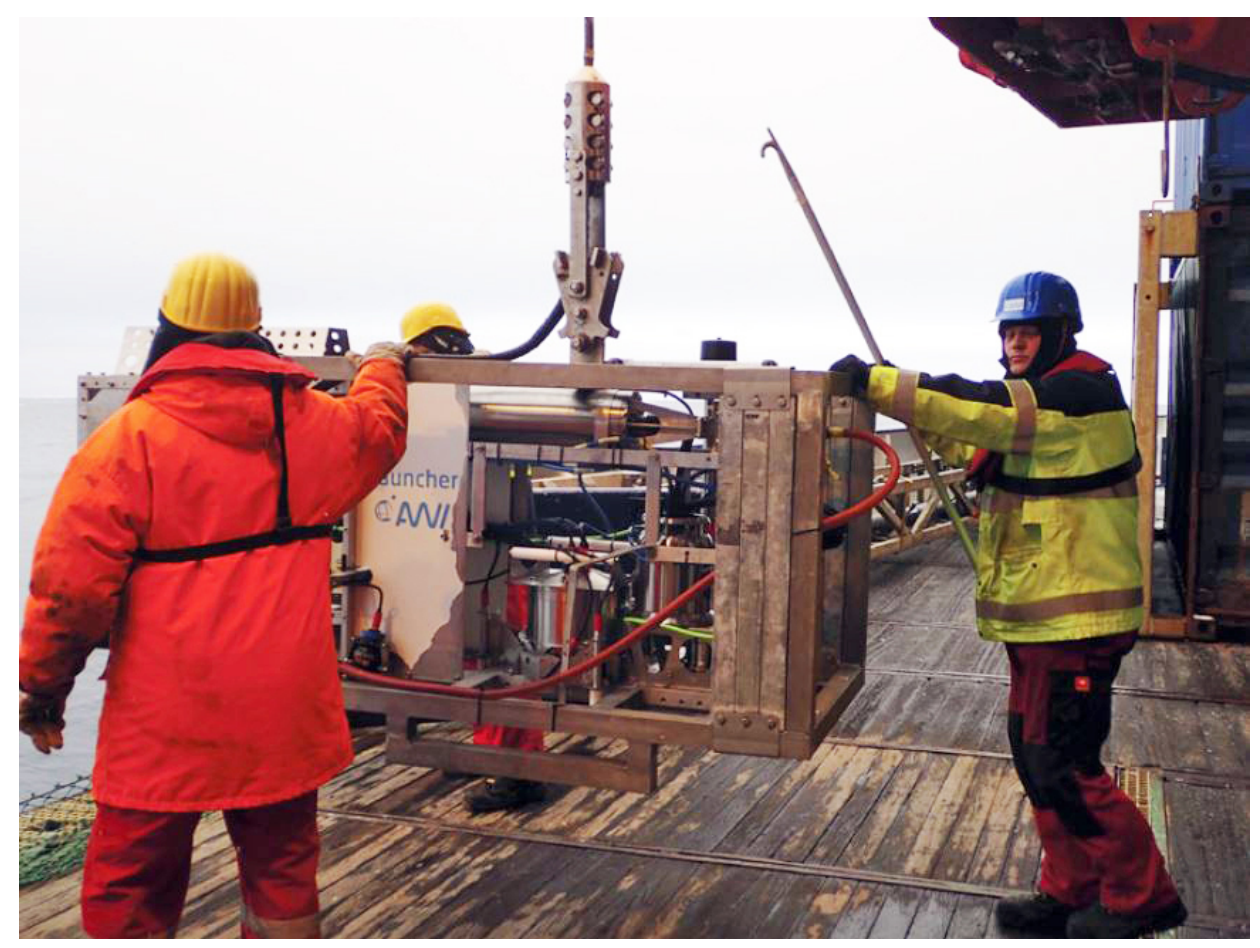

Figure 1. The Ocean Floor Observation and Bathymetry System (OFOBS) of the Alfred Wegener Institute (AWI), Helmholtz Centre for Polar and Marine Research, deployed from the RV Polarstern during cruise PS118 in the waters east of the Antarctic Peninsula and on the flanks of the Powell Basin (February-April 2019).

During RV Polarstern expedition PS118 (9 February10 April 2019) (Dorschel, 2019b) the OFOBS was deployed 11 times, conducting concurrent high-resolution still-image, video and acoustic surveys across diverse and contrasting regions of the Antarctic seafloor (Fig. 2). Ice conditions during the cruise were harsh, though a north-south transect from the Weddell Sea continental shelf to the northwestern continental shelf edge of the Powell Basin was completed, with stations on the Weddell Sea plateau, Nachtigaller Shoal (Dorschel et al., 2014), and flanks and rim of the Powell Basin investigated (Table 1). The forward-facing acoustic camera allows for the towed OFOBS operator to be aware of steep structures or rising seafloor ahead of the device and allows for ample time to winch the system to a safer height. This allowed for use even in heavy ice, with a minimal ability for ship manoeuvre, and close to the steep flanks of the Powell Basin, allowing for collection of this novel dataset.

The PS118 OFOBS data were collected with the same cameras, illumination regime and deployment protocols as mounted on the previous AWI towed camera sled system (Ocean Floor Observation System (OFOS)), used to survey the Antarctic seafloor during previous recent RV Polarstern expeditions (Piepenburg et al., 2017), such as PS81, also to the western Weddell Sea area in 2013 (Gutt, 2013; Gutt et al., 2016), and PS96, to the southeastern Weddell Sea in 2015/16 (Schröder et al., 2016). By continuing to mount the same camera systems, observations made during PS118 can be most readily compared with those made during the previous expeditions, uncomplicated by methodological problems relating to variabilities in camera performance, flight height or illumination (Schoening et al., 2020).

The OFOBS data collected during PS118 and presented here are of use for a range of scientific studies, such as:

1. assessment of epibenthic megafauna communities observed at several sites along a south-north transect from the Weddell Sea Antarctic Peninsula continental shelf to the Powell Basin

2. spatial comparison of these observed shelf and basin megafauna communities with those observed with the very similar OFOS towed device sled during recent cruises

3. a temporal picture of seafloor communities occupying these seafloor regions in 2019 , for comparison with future studies following continued ice loss

4. an extensive set of seafloor images from several locations on the Powell Basin flank, a region of southern seafloor sparsely surveyed to date. 


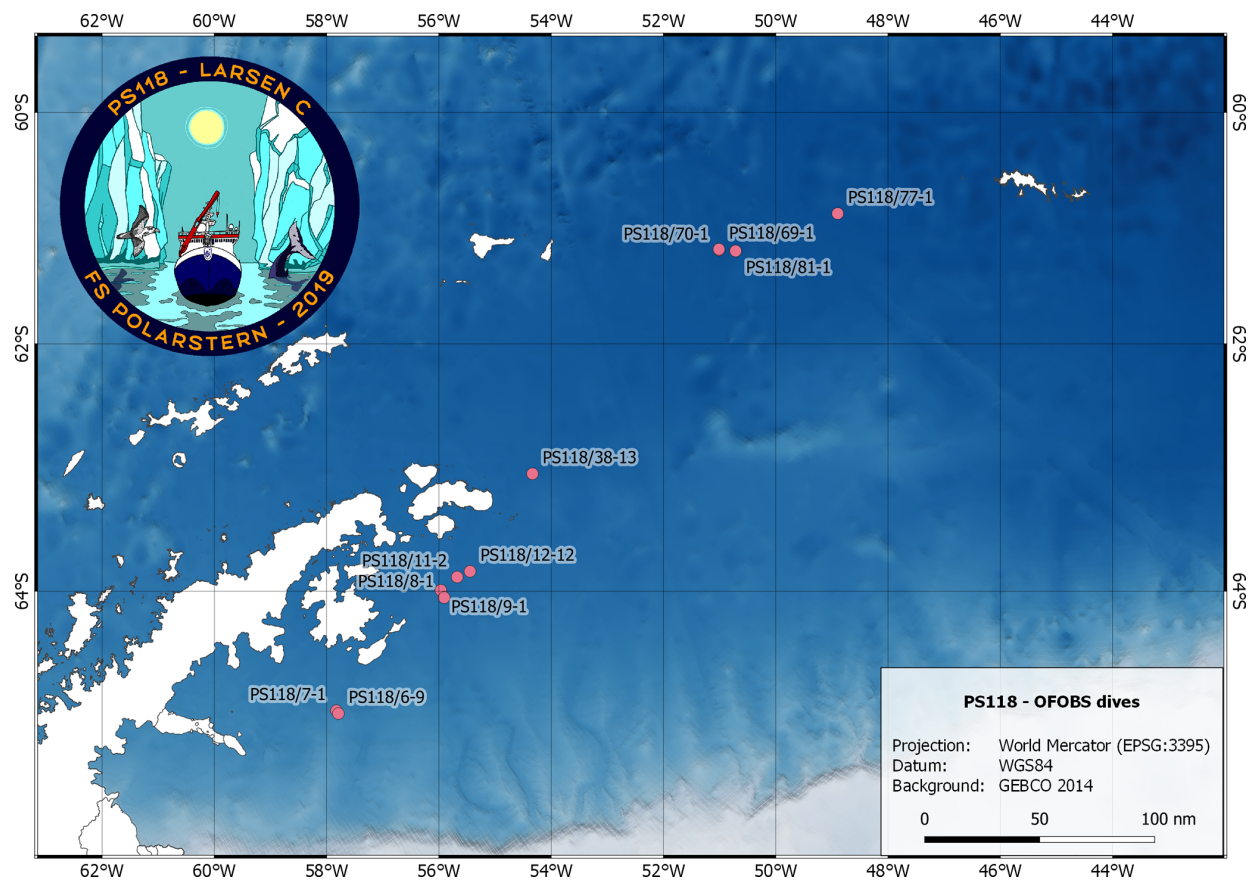

Figure 2. Regional map showing the positions of OFOBS deployments made during RV Polarstern cruise PS118.

Table 1. Locations of OFOBS deployments during PS118. Start and end position coordinates and times are given, in addition to the numbers of timer and hotkey images collected during each deployment.

\begin{tabular}{|c|c|c|c|c|c|c|c|c|c|c|}
\hline Station & Region & $\begin{array}{r}\text { Date } \\
\text { (DD.MM.YYYY) }\end{array}$ & $\begin{array}{r}\text { Start } \\
(\text { UTC) }\end{array}$ & $\begin{array}{r}\text { End } \\
\text { (UTC) }\end{array}$ & $\begin{array}{r}\text { Latitude } \\
\text { start }\end{array}$ & $\begin{array}{r}\text { Longitude } \\
\text { start }\end{array}$ & $\begin{array}{r}\text { Latitude } \\
\text { end }\end{array}$ & $\begin{array}{r}\text { Longitude } \\
\text { end }\end{array}$ & $\begin{array}{r}\text { Timer } \\
\text { images }\end{array}$ & $\begin{array}{l}\text { Hotkey } \\
\text { images }\end{array}$ \\
\hline PS118_6 & Weddell Sea & 06.03 .2019 & 05:01 & $09: 33$ & -64.939363 & -57.791526 & -64.929378 & -57.818072 & 1314 & 90 \\
\hline PS118_7 & Weddell Sea & 06.03.2019 & $19: 25$ & 20:08 & -64.918268 & -57.824799 & -64.914652 & -57.826477 & 259 & 28 \\
\hline PS118_8 & Weddell Sea & 11.03.2019 & 12:02 & $15: 45$ & -64.049462 & -55.90669 & -64.007332 & -55.908186 & 891 & 73 \\
\hline PS118_9 & Weddell Sea & 12.03.2019 & 06:00 & $06: 51$ & -63.991755 & -55.965738 & -63.993996 & -55.968168 & 319 & 4 \\
\hline PS118_11 & Nachtigaller & 13.03.2019 & $20: 14$ & $22: 25$ & -63.888204 & -55.675914 & -63.887744 & -55.656926 & 690 & 7 \\
\hline PS118_12 & Weddell Sea & 15.03.2019 & $01: 28$ & $05: 55$ & -63.844375 & -55.447947 & -63.844602 & -55.446939 & 1547 & 5 \\
\hline PS118_38 & Weddell Sea & 23.03.2019 & 05:01 & $06: 31$ & -63.067100 & -54.334116 & -63.073675 & -54.3194 & 379 & 11 \\
\hline PS118_39 & Powell Basin & 23.03.2019 & $18: 46$ & 09:56 & -61.914657 & -53.323264 & -61.865707 & -53.324424 & 3667 & 140 \\
\hline PS118_69 & Powell Basin & 31.09.2019 & $01: 52$ & $16: 00$ & -61.192316 & -50.996506 & -61.192854 & -51.085361 & 2655 & 68 \\
\hline PS118_77 & Powell Basin & 01.04.2019 & 21:08 & $21: 48$ & -60.8888864 & -48.896518 & -60.887241 & -48.905883 & 153 & 5 \\
\hline PS118_81 & Powell Basin & 03.04.2019 & $21: 24$ & 09:31 & -61.213897 & -50.716745 & -61.186405 & -50.672902 & 373 & \\
\hline
\end{tabular}

\section{Materials and methods}

\subsection{Ocean Floor Observation and Bathymetry System (OFOBS)}

The OFOBS is a state-of-the-art towed camera and acoustic survey sled recently developed by the Deep-Sea Ecology and Technology group of AWI for benthic polar research in ice-covered environments (Purser et al., 2018). The device was deployed during PS118 as described in Purser et al. (2018), taking images under comparable illumination conditions and flight heights and with the same camera systems as were mounted on the OFOS sled during the PS86 and PS96 cruises in 2013 and 2015/16, respectively (Piepenburg et al., 2017). OFOBS positioning during deployments was carried out with the iXBlue Posidonia ultra-short base line (USBL) system used by RV Polarstern, localising the relative position of the OFOBS to the vessel (itself deriving its position from a satellite-based global navigation satellite system (GNSS). Every few seconds (depending on deployment depth) the OFOBS received a new position fix, which was used to position stamp each collected image against a UTC timestamp. During PS118, a stable position fix was attained with an accuracy of approximately $0.2 \%$ of the slant range from the ship to the subsea unit. Environmental and operational factors, such as ice coverage and vessel speed could result in a slanted tether cable, though for the deployment depths made during PS118 a positional accuracy of within $\sim 20 \mathrm{~m}$ was likely maintained throughout. Images were taken at 26-megapixel resolution with the camera sys- 


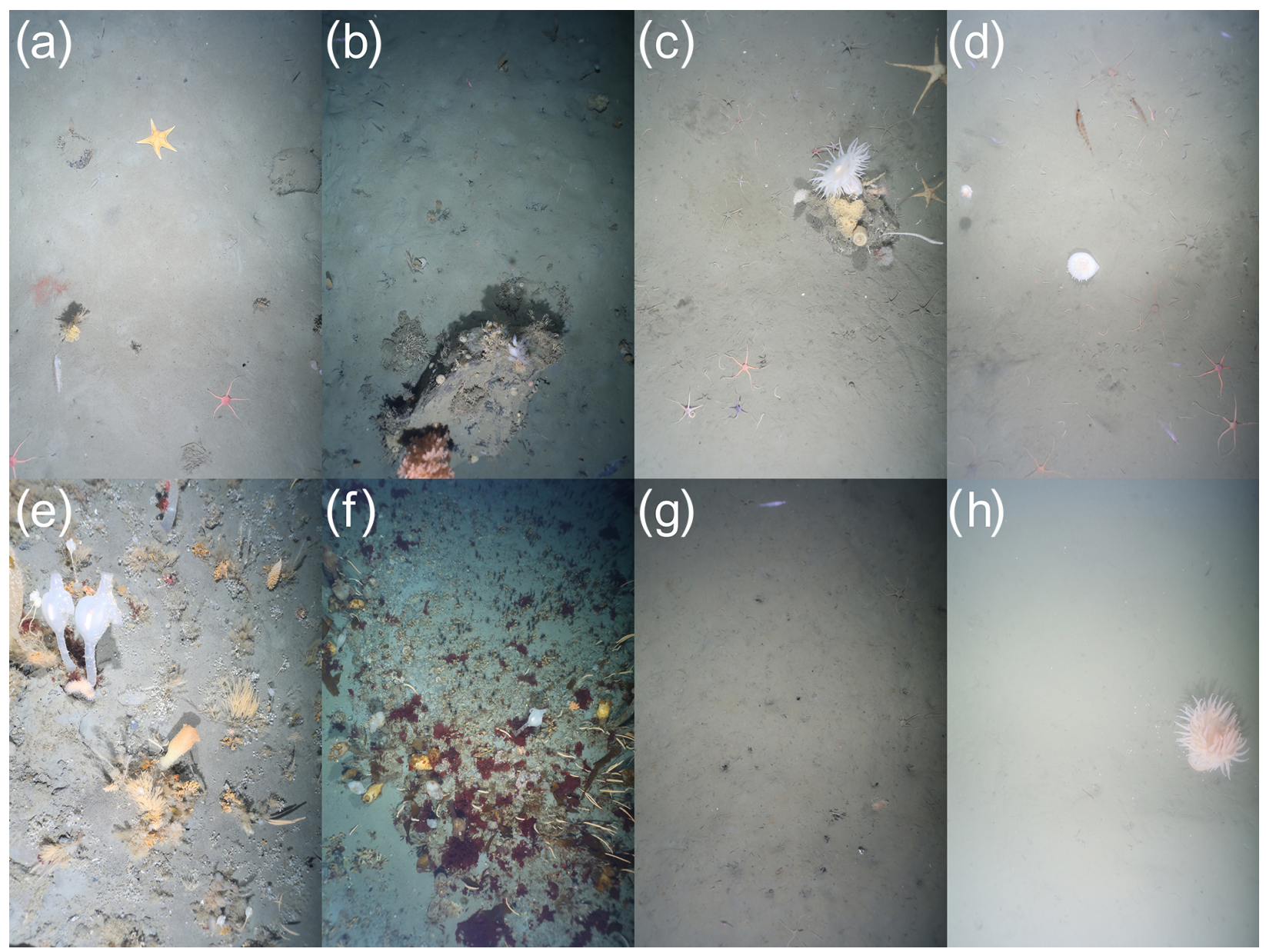

Figure 3. Typical seafloor images collected from each of the OFOBS surveys made of the Weddell Sea seafloor during RV Polarstern cruise PS118. (a) Station PS118_6, hotkey_2019_03_06 at 05_07_31. (b) Station PS118_7, hotkey_2019_03_06 at 19_36_28. (c) Station PS118_8, hotkey_2019_03_11 at 14_33_24. (d) Station PS118_9,timer_2019_03_12 at 06_01_06. (e) Station PS118_11, timer_2019_03_13 at 20_14_04. (f) Station PS118_11, timer_2019_03_13 at 22_18_47. (g) Station PS118_12, timer_2019_03_15 at 01_29_36. (h) Station PS118_38, hotkey_2019_03_23 at 06_27_00. All images are presented here and in the dataset with no manipulation or colour correction.

tem (iSiTEC, Canon EOS 5D Mark III) with an automated timer (for the majority of images, these were taken with a frequency of about one image every $20 \mathrm{~s}$ ). Additional images taken at the discretion of the operator. These two image categories are distinguished in the dataset as "hotkey" and "timer" images - designations automatically incorporated into the timestamped filenames. Hotkey images were commonly taken on the first observation of a particular fauna species or to record a feature of interest, such as a whale fall or interesting geological structure. No processing stages were applied to the maximum-resolution .jpeg data collected from the camera, which are provided here at the maximum acquired resolution.

Throughout all of these deployments the OFOS and OFOBS systems were equipped with three red sizing lasers (FLEXPOINT) (Purser et al., 2018; Purser and Sablotny, 2020), arrayed in an equilateral triangle with $50 \mathrm{~cm}$ spacing around the still-image camera housing. This laser array ensures that each image recorded has three red dots near the centre of the image, each spaced by $50 \mathrm{~cm}$. These dots can be used in subsequent analysis to determine accurately the area covered by a particular image. Throughout PS118 the OFOBS was deployed approximately $1.5-2 \mathrm{~m}$ above the seafloor, giving a coverage within each collected image of $4-6 \mathrm{~m}^{2}$. Illumination of the seafloor was provided by four downward-facing SeaLight Sphere 3150 LED lights positioned in the corners of the main OFOBS frame, with two additional strobe lights (iSiTEC UW-Blitz 250, through the lens (TTL) driven) firing concurrently with image collection. Throughout all deployments, HD (high-definition) video data were recorded by the OFOBS for the duration of each dive with an HD video recorder (iSiTEC, Sony FCB-H11) (Purser et al., 2018). 


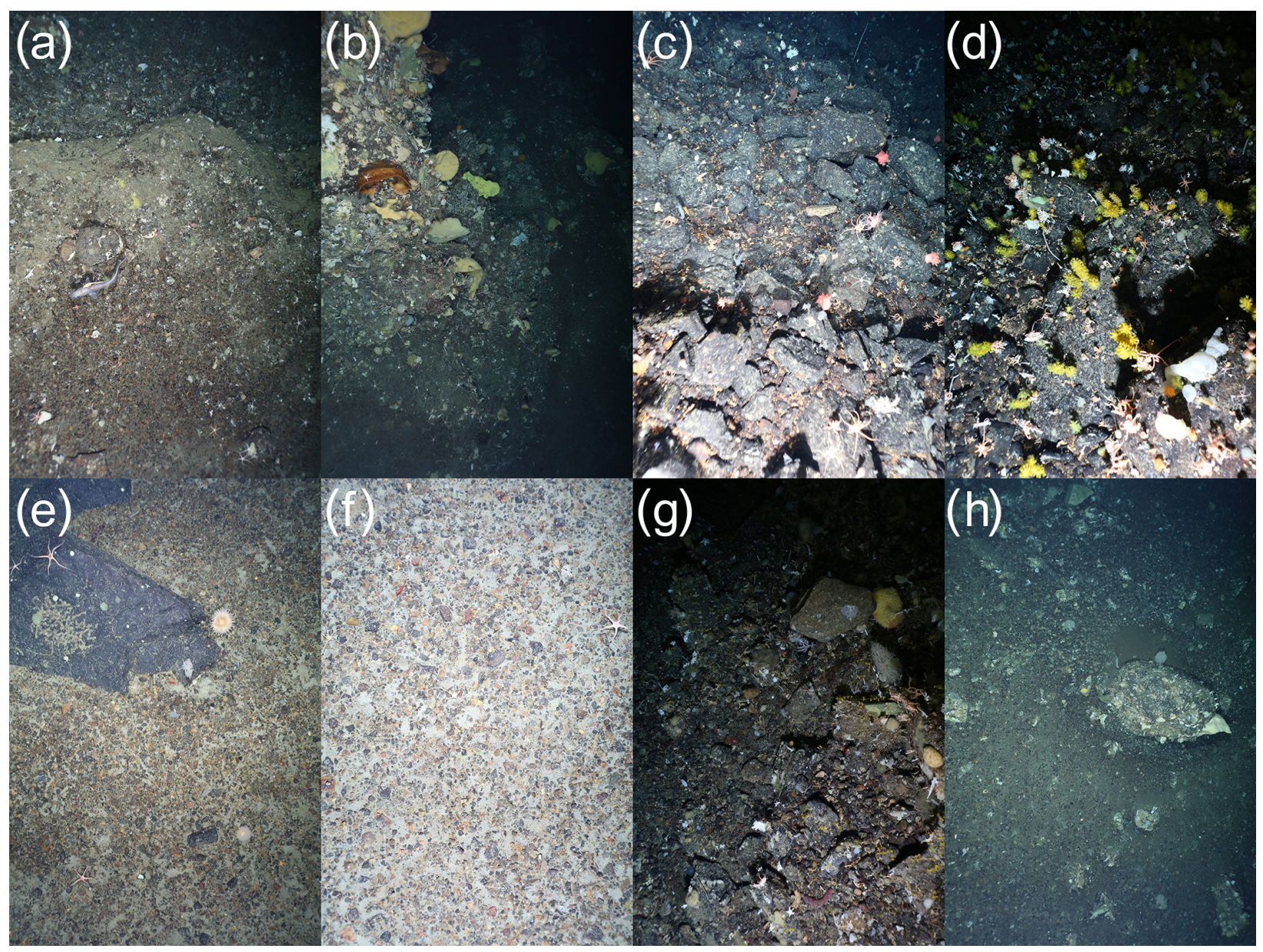

Figure 4. Typical seafloor and cliff escarpment images collected during OFOBS surveys of the Powell Basin flanks during RV Polarstern cruise PS118. (a) Station PS118_39, hotkey_2019_03_23 at 23_21_46. (b) Station PS118_39, timer_2019_03_25 at 18_50_09. (c) Station PS118_69, hotkey_2019_03_31 at 12_20_55. (d) Station PS118_69, hotkey_2019_03_31 at 14_10_56. (e) Station PS118_77, timer_2019_04_01 at 20_39_51. (f) Station PS118_77, timer_2019_04_01 at 20_11_32. (g) Station PS118_81, timer_2019_04_04 at 00_25_31. (h) Station PS118_81, timer_2019_04_04 at 02_27_33. All images are presented here and in the dataset with no manipulation or colour correction.

\subsection{Field sampling}

\subsubsection{Weddell Sea sampling}

OFOBS surveys were carried out in a roughly south-north transect from the Weddell Sea continental shelf of the Antarctic Peninsula to the northern Powell Basin. In total, seven OFOBS deployments were made between 65 and $62^{\circ} \mathrm{S}$ (Table 1 and Fig. 2). With the exception of an OFOBS deployment across the Nachtigaller Shoal (Dorschel et al., 2014) (station PS118/11-2), the seafloor in these regions was observed to be predominantly made up of soft material with occasional drop stones present (Fig. 3).

\subsubsection{Powell Basin sampling}

Four successful OFOBS deployments were made on the flanks and rim of the Powell Basin (Table 1 and Fig. 2).
Three of these deployments, PS118/39-1, PS118/69-1 and PS118/81-1, benefitted from the equipping of the OFOBS sled with a forward-looking sonar (Purser et al., 2018). This sensor allowed for the OFOBS to be used over very steep terrain with minimum risk, by giving advance warning of any hard structures $\sim 30 \mathrm{~m}$ ahead of the sled. The majority of towed sleds, such as the OFOS, are less capable in highrelief regions, where snagging on tall structures such as cliffs or vent structures can occur. With the OFOBS, the $\sim 30 \mathrm{~m}$ warning of approach is sufficient to allow the operators to commence winching of the system in good time to minimise the risk of impact of the sled with the seafloor whilst still collecting usable image data. These datasets each cover many hundreds of metres of the Powell Basin flank walls, visually surveying these traditionally difficult-to-investigate regions of seafloor (Fig. 4). 


\section{Data availability}

All seafloor images collected with the OFOBS system are available from the data publisher PANGAEA. No preprocessing or processing stages were applied prior to upload, with no colour correction or light-vignetting algorithms applied. These images are provided with georeferenced positions for each image, as derived from the Posidonia system (https://doi.org/10.1594/PANGAEA.911904; Purser et al., 2020). The full cruise track is also available via PANGAEA (https://doi.org/10.1594/PANGAEA.901319; Dorschel, 2019a) with information on additional environmental and scientific data collected during the cruise given in the PS118 cruise report (Dorschel, 2019b). Video data collected via the OFOBS system are available from the authors on request. In addition to the image data presented in this paper, the multibeam data concurrently collected by the OFOBS device has also been uploaded to PANGAEA and will be available from April 2021 for open-access download or on request from the authors.

Author contributions. AP applied for the secondary user time for the PS118 cruise, conceived of the investigation and ran the data collection campaign. BD was the chief scientist for the PS118 expedition. SD, LH, HS, HG and AN helped run the OFOBS platform. AP, HG, KJ, DP, CR and BD determined sampling strategies for the OFOBS and aided in data collection. AP prepared the paper with contributions from all co-authors.

Competing interests. The authors declare that they have no conflict of interest.

Acknowledgements. The captain and crew of RV Polarstern expedition PS118 are thanked for their support and interest in the OFOBS deployments conducted during the cruise. Ulrich Hoge is thanked for his assistance in installing the OFOBS system prior to cruise commencement.

Review statement. This paper was edited by David Carlson and reviewed by Katrien Van Landeghem and one anonymous referee.

\section{References}

Barnes, D. K. A. and Tarling, G. A.: Polar oceans in a changing climate, Curr. Biol., 27, R454-R460, https://doi.org/10.1016/j.cub.2017.01.045, 2017.

Chaabani, S., López-González, P. J., Casado-Amezú, P., Pehlke, H., Weber, L., Martínez-Baraldés, I., and Jerosch, K.: Ecological niche modelling of cold-water corals in the Southern Ocean (N Antarctic), present distribution and future projections due to temperature changes, Mar. Ecol. Prog. Ser., 628, 73-93, https://doi.org/10.3354/meps13085, 2019.
Dorschel, B.: Links to master tracks in different resolutions of POLARSTERN cruise PS118, Punta Arenas - Punta Arenas, 201902-09-2019-04-08, Alfred Wegener Institute, Helmholtz Centre for Polar and Marine Research, Bremerhaven, PANGAEA, https://doi.org/10.1594/PANGAEA.901319, 2019a.

Dorschel, B.: The Expedition PS118 of the Research Vessel POLARSTERN to the Weddell Sea in 2019, Berichte Zur PolarMeeresforsch. Rep. Polar Mar. Res., available at: https://epic. awi.de/id/eprint/50139/ (last access: 5 February 2020), 2019 b.

Dorschel, B., Gutt, J., Piepenburg, D., Schröder, M., and Arndt, J. E.: The influence of the geomorphological and sedimentological settings on the distribution of epibenthic assemblages on a flat topped hill on the over-deepened shelf of the western Weddell Sea (Southern Ocean), Biogeosciences, 11, 3797-3817, https://doi.org/10.5194/bg-11-3797-2014, 2014.

Fillinger, L., Janussen, D., Lundälv, T., and Richter, C.: Rapid Glass Sponge Expansion after Climate-Induced Antarctic Ice Shelf Collapse, Curr. Biol., 23, 1330-1334, https://doi.org/10.1016/j.cub.2013.05.051, 2013.

Griffiths, H. J., Meijers, A. J. S., and Bracegirdle, T. J.: More losers than winners in a century of future Southern Ocean seafloor warming, Nat. Clim. Change, 7, 749-754, https://doi.org/10.1038/nclimate3377, 2017.

Gutt, J., Alvaro, M. C., Barco, A., Böhmer, A., Bracher, A., David, B., De Ridder, C., Dorschel, B., Eléaume, M., Janussen, D., Kersken, D., López-González, P. J., Martínez-Baraldés, I., Schröder, M., Segelken-Voigt, A., and Teixidó, N.: Macroepibenthic communities at the tip of the Antarctic Peninsula, an ecological survey at different spatial scales, Polar Biol., 39, 829-849, https://doi.org/10.1007/s00300-015-1797-6, 2016.

Gutt, J., Arndt, J., Kraan, C., Dorschel, B., Schröder, M., Bracher, A., and Piepenburg, D.: Benthic communities and their drivers: A spatial analysis off the Antarctic Peninsula, Limnol. Oceanogr., 64, 2341-2357, https://doi.org/10.1002/lno.11187, 2019.

Han, H., Lee, S., Kim, J.-I., Kim, S. H., and Kim, H.: Changes in a Giant Iceberg Created from the Collapse of the Larsen C Ice Shelf, Antarctic Peninsula, Derived from Sentinel-1 and CryoSat-2 Data, Remote Sens., 11, 404, https://doi.org/10.3390/rs11040404, 2019.

Piepenburg, D., Buschmann, A., Driemel, A., Grobe, H., Gutt, J., Schumacher, S., Segelken-Voigt, A., and Sieger, R.: Seabed images from Southern Ocean shelf regions off the northern Antarctic Peninsula and in the southeastern Weddell Sea, Earth Syst. Sci. Data, 9, 461-469, https://doi.org/10.5194/essd-9-461-2017, 2017.

Purser, A. and Sablotny, B.: Hochauflösende Fotos bei absoluter Dunkelheit, Photonics News, 88, 10-11, 2020.

Purser, A., Marcon, Y., Dreutter, S., Hoge, U., Sablotny, B., Hehemann, L., Lemburg, J., Dorschel, B., Biebow, H., and Boetius, A.: Ocean Floor Observation and Bathymetry System (OFOBS): A new Towed Camera/Sonar System for Deep-Sea Habitat Surveys, IEEE J. Ocean. Eng., 44, 87-99, https://doi.org/10.1109/JOE.2018.2794095, 2018.

Purser, A., Hehemann, L., Dreutter, S., Dorschel, B., and Nordhausen, A.: OFOBS Seafloor images from the Antarctic Peninsula and Powell Basin, collected during RV POLARSTERN cruise PS118, Alfred Wegener Institute, Helmholtz Centre for Polar and Marine Research, Bremerhaven, PANGAEA, https://doi.org/10.1594/PANGAEA.911904, 2020. 
Rott, H., Skvarca, P., and Nagler, T.: Rapid Collapse of Northern Larsen Ice Shelf, Antarctica, Science, 271, 788-792, https://doi.org/10.1126/science.271.5250.788, 1996.

Scambos, T., Hulbe, C., and Fahnestock, M.: Climate-Induced Ice Shelf Disintegration in the Antarctic Peninsula, in: Antarctic Peninsula Climate Variability: Historical and Paleoenvironmental Perspectives, American Geophysical Union (AGU), 79-92, available at: https://agupubs.onlinelibrary.wiley.com/doi/abs/10. 1029/AR079p0079 (last access: 10 February 2021), 2013.

Schoening, T., Purser, A., Langenkämper, D., Suck, I., Taylor, J., Cuvelier, D., Lins, L., Simon-Lledó, E., Marcon, Y., Jones, D. O. B., Nattkemper, T., Köser, K., Zurowietz, M., Greinert, J., and Gomes-Pereira, J.: Megafauna community assessment of polymetallic-nodule fields with cameras: platform and methodology comparison, Biogeosciences, 17, 3115-3133, https://doi.org/10.5194/bg-17-3115-2020, 2020.
Schröder, M., Ryan, S., and Wisotzki, A.: Physical oceanography during POLARSTERN cruise PS96 (ANT-XXXI/2 FROSN), Alfred Wegener Institute, Helmholtz Centre for Polar and Marine Research, Bremerhaven, PANGAEA, https://doi.org/10.1594/PANGAEA.859040, 2016.

Shepherd, A., Wingham, D., Payne, T., and Skvarca, P.: Larsen Ice Shelf Has Progressively Thinned, Science, 302, 856-859, https://doi.org/10.1126/science.1089768, 2003.

Skvarca, P.: Fast recession of the northern Larsen Ice Shelf monitored by space images, Ann. Glaciol., 17, 317-321, https://doi.org/10.3189/S0260305500013033, 1993. 